\title{
Increasing productivity and management of IRT business "kalian kripik" In Kelurahan Karang Berombak, Kecamatan Medan Barat, Kota Medan
}

\author{
Emalisa $^{1^{*}, \text { Iskandarini }^{2}, \text { Lily Fauzia }^{3} \text {, Satia Negara Lubis }}{ }^{4}$, \\ Mozart Bahauddin Barus ${ }^{5}$ \\ 1.2,3,4,5 Faculty of Agriculture, Universitas Sumatera Utara, Medan, Indonesia \\ *Email: emalisa@usu.ac.id
}

\begin{abstract}
After the idea, production machinery and equipment is the capital that a production business must have in order to run. The more complete and modern the tools and machines that a business has, the more business productivity will increase, which in turn can increase business revenues. This service aims to increase the productivity and management of IRT 'Kalian Kripik' which produces onion cakes from various original flavors from agricultural products such as potatoes, sweet potatoes and sweet potatoes. Devotion is done by providing science and technology assistance in the form of Ampia machines and Digital Scales, as well as business management training in the form of training in calculating depreciation costs, bookkeeping, and business analysis. After this service, IRT 'Kalian Kripik' has been able to improve the quality and quality of its products. The results of dedication show that with the help of machines and tools that are given by the Partner, they can improve the quality of their products, weigh the ingredients and production more accurately, be able to manage business better in the form of bookkeeping activities, calculation of depreciation and business analysis.
\end{abstract}

Keyword: machinery, tools, quality, bookkeeping, depreciation, business analysis

\begin{abstract}
Abstrak
Setelah ide, mesin dan peralatan produksi merupakan modal yang harus dimiliki sebuah kegiatan usaha produksi agar bisa berjalan. Semakin lengkap dan modern alat dan mesin yang dimiliki suatu usaha maka semakin meningkat produktivitas usaha tersebut, selanjutnya dapat meningkatkan pendapatan usaha tersebut. Pengabdian ini bertujuan untuk meningkatkan produktivitas dan manajemen IRT 'Kalian Kripik' yang memproduksi kue bawang dari berbagai rasa asli dari produk pertanian seperti kentang, ubi ungu dan daun ubi. Pengabdian dilakukan dengan memberikan bantuan Iptek berupa mesin Ampia dan Timbangan Digital, serta pelatihan manajemen usaha berupa pelatihan perhitungan biaya penyusutan (depresiasi), pembukuan, dan analisis usaha. Setelah kegiatan pengabdian ini IRT 'Kalian Kripik telah dapat meningkatkan kualitas dan kualitas produknya. Hasil pengabdian menunjukkan dengan bantuan mesin dan alat yang diperikan Mitra dapat meningkatkan kualitas produknya, melakukan penimbangan bahan dan hasil produksi dengan lebih akurat, dapat melakukan manajemen usaha dengan lebih baik berupa kegiatan pembukuan, perhitungan penyusutan dan analisis usaha.
\end{abstract}

Kata Kunci: mesin, alat, kualitas, pembukuan, penyusutan, analisis usaha 


\section{PENDAhuluan}

Setelah ide, mesin dan peralatan produksi merupakan modal yang harus dimiliki sebuah kegiatan usaha produksi agar bisa berjalan. Semakin lengkap dan modern alat dan mesin yang dimiliki suatu usaha maka semakin meningkat produktivitas usaha tersebut, sekaligus dapat meningkatkan pendapatan usaha tersebut. IRT (Industri Rumah Tangga) merupakan salah satu lapangan pekerjaan yang masih bisa terus dikembangkan, dengan penambahan modal produksi IRT selanjutnya dapat membuka lapangan kerja bagi masyarakat di sekitar lokasi IRT berada.

IRT 'Kalian Kripik' yang merupakan Mitra 1 dalam program Pengabdian pada Masyarakat ini adalah salah satu IRT yang ada di Kota Medan. IRT ini sudah berdiri sejak tahun 2013. IRT ini memproduksi keripik kue bawang dengan berbagai rasa asli alami, dengan menggunakan berbagai bahan dari produk pertanian segar Indonesia seperti kentang, ubi ungu dan daun singkong (daun ubi tumbuk), serta menggunakan berbagai bumbu dan rempah segar lainnya.

IRT 'Kalian Kripik' yang merupakan Mitra 1 dalam program Pengabdian pada Masyarakat ini adalah salah satu IRT yang ada di Kota Medan. IRT ini sudah berdiri sejak tahun 2013. IRT ini memproduksi keripik kue bawang dengan berbagai rasa asli alami, dengan menggunakan berbagai bahan dari produk pertanian segar Indonesia seperti kentang, ubi ungu dan daun singkong (daun ubi tumbuk), serta menggunakan berbagai bumbu dan rempah segar lainnya.

Produk IRT ini sudah mendapat sertifikat halal MUI sejak tahun 2015 secara gratis dengan bantuan Dinas Ketahanan Pangan Kota Medan, yang selanjutnya dapat diperpanjang secara berkala. Namun mereka belum pernah menerima bantuan dari pemerintah dan pihak lain dalam bentuk mesin maupun alat produksi.

Pada hari-hari biasa Mitra menghasilkan produk rata-rata kurang lebih $5 \mathrm{~kg}$ / hari atau 150 $\mathrm{kg} /$ bulan. Sedangkan menjelang Hari Besar Idul Fitri produksi mereka mencapai 500-700 kg/ bulan. Jumlah Tenaga Kerja Tetap Dalam Keluarga terdiri dari 5 orang dan Tenaga Kerja Luar Keluarga Tidak Tetap sebanyak 4 orang.

Pemasaran produk Mitra ini sebagian besar dijual melalui beberapa toko oleh-oleh dan supermarket yang ada di Kota Medan, seperti di Supermarket Suzuya, Gerai DKP, Sentra UMK, dan Toko Kue Mulaka dengan sistem konsinyasi. Sistem konsinyasi artinya IRT menitip produk keripiknya di Toko/Gerai/Supermarket (pihak ke2) dan selanjutnya pihak ke2 akan membayar produk yang dititipkan kepada mereka jika sudah laku terjual. Sebagian lain penjualan dilakukan secara kes/bayar tunai melalui beberapa pedagang pengecer dan ke beberapa daerah di luar Kota Medan, seperti Aceh, Pakan Baru, Kisaran, dan lain-lain terutama di saat menjelang Hari Raya Idul Fitri dengan sistem pembayaran tunai.

\section{METODE PELAKSANAAN}

\subsection{Tempat dan Waktu Pelaksanaan Kegiatan}

Pengabdian ini di lakukan di Kota Medan dengan Mitra IRT Kalian Kripik yang memproduksi kue bawang dengan beraneka rasa alami, seperti ketang, ubi ungu, daun ubi tumbuk, dll.

Metode pelaksanaan pengabdian kepada masyarakat untuk mengatasi permasalahan mitra adalah dengan pemberian bantuan dan pelatihan penggunaan alat dan mesin produksi: Mesin Pemipih adonan (Noodle Cutter Machine) dan Timbangan Digital. Serta memberikan beberapa pelatihan untuk meningkatkan manajemen usaha dengan metode learning by doing, yaitu pelatihan pembuatan pembukuan, inventarisasi modal tetap usaha dan perhitungan penyusutan, serta analisis usaha. 


\section{HASIL DAN PEMBAHASAN}

Pada tahap awal Tim pelaksana pengabdian kepada masyarakat melakukan diskusi dan konsolidasi dengan Mitra untuk mengetahui permasalahan yang dihadapi Mitra dan menentukan masalah yang paling urgen untuk segera diselesaikan oleh mitra..

Pada tahap berikutnya Tim Pengabdian dengan Mitra melakukan diskusi untuk mendapatkan jalan keluar yang bisa diambil untuk mengatasi masalah tersebut. Antara lain Mitra 1 membutuhkan bantuan Mesin Pemipih adonan (Noodle Cutter Machine) dan Timbangan Digital, pelatihan pembukuan, analisis usaha dan perhitungan penyusatan alat dan mesin.

Pada bulan Agustus 2019 dilakukan pembelian Mesin Pemipih adonan (Noodle Cutter Machine) dan Timbangan Digital dan kemudian diserahkan kepada Mitra, untuk kemudian digunakan mitra dalam memproduksi kripik dan menimbang hasil produksinya.

Berikut adalah gambar Mesin Pemipih adonan dan Timbangan Digital yang telah diserahkan kepada Mitra.

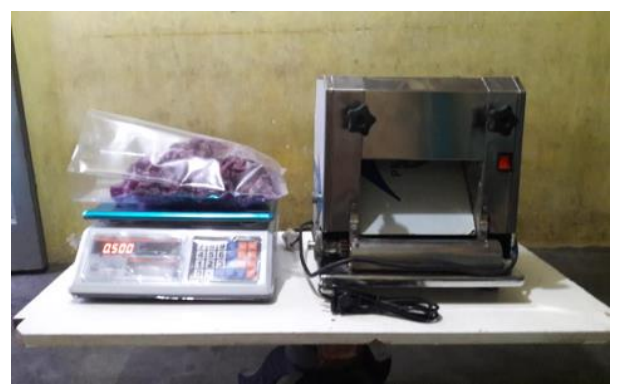

Gambar. Mesin Pemipih Adonan dan Timbangan Digital

Kegiatan pengabdian selanjutnya adalah pelatihan pembukuan dan analisis usahatani yang ditujukan kepada Mitra agar dapat mencatat dan sekaligus menghitung semua pengeluaran dan pendapatan usaha mereka. Kegiatan ini dilakukan agar mitra dapat membuat perencanaan yang lebih baik dalam kegiatan usaha mereka selanjutnya.

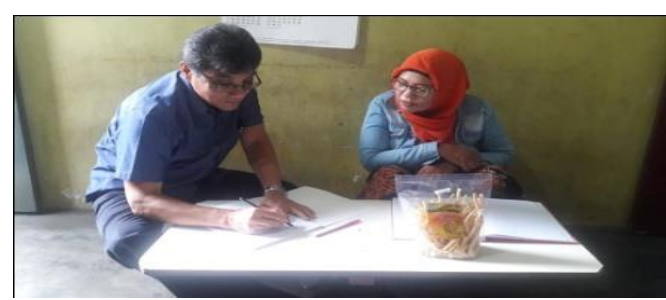

Gambar. Pelatihan Pembukuan

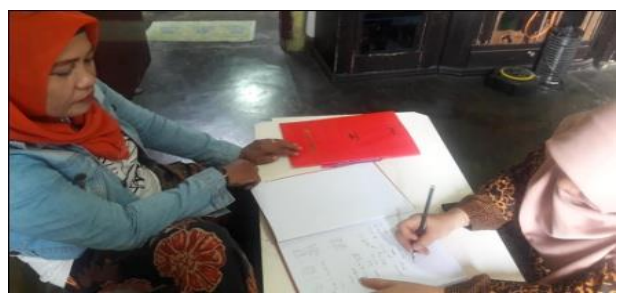

Gambar. Pelatihan Analisis Usaha 
Mitra juga dilatih untuk bisa menghitung biaya penyusutan alat dan mesin produksinya, dengan tujuan agar Mitra mengetahui berapa uang yang harus disisihkannya dalm bentuk tabungan setiap bulannya sebagai dana cadangan untuk membeli alat dan mesin produksi yang baru jika yang lama sudah tidak dapat digunakan lagi di kemudian hari. Sehingga usaha mereka bisa berkelanjutan.

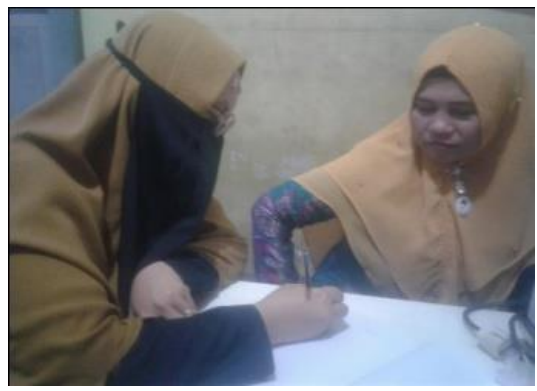

Gbr. Pelatihan Perhitungan Penyusutan

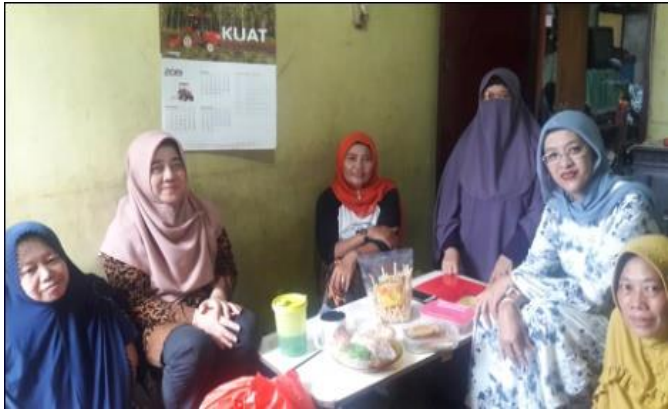

Gbr. Bincang-bincang Pemasaran

\section{KESIMPULAN}

Usaha produksi IRT Kalian Kripik merupakan salah satu usaha yang memiliki prospek untuk dikembangkan tidak saja untuk meningkatkan pendapatan produsen juga dapat membuka lapangan kerja bagi masyarakat sekitarnya.

1. Bantuan alat dan mesin yang diterima Mitra telah dipergunakan untuk melakukan kegitan kegiatan produksi dan pemasaran.

2. Mitra mulai melakukan pembukuan usaha mereka

3. Mitra mengetahui pendapatan bersih yang mereka dapatkan dalam 1 kali produksi.

4. Mitra sudah mengetahui jumlah dana yang harus dia sisihkan setiap bulan sebagai dana cadangan untuk membeli mesin dan alat produksi jika kelak tidak dapat dipergunakan lagi.

\section{UCAPAN TERIMA KASIH}

Tim pengabdian pada masyarakat mengucapkan terima kasih kepada pihak LPPM USU yang telah memberikan dana kepada pengabdian ini. Terima kasih juga kepada pihak mitra yang telah koopratif di dalam pelaksanaan pengabdian ini. 


\section{DAFTAR PUSTAKA}

Adiwilaga, A. 1982. Ilmu Usahatani. Bandung: Penerbit Alumni.

Emalisa. 2011. Perhitungan Penyusutan (Depresiasi) pada Modal Tetap sebagai strategi keberlanjutan Usahatani. Medan : Perpustakaan Pusat USU.

Murpi, S. Dan D.T. Iskandar. 2011. Manajemen Bisnis untuk Orang Awam. Jakarta: Niaga Swadaya.

Faruq, I. 2018. Memulai Bisnis Online Terbaru Tanpa Modal Yang Mudah Bagi Pemula. https://centrausaha.com/bisnis-online/ 